\title{
Collaborative Multimedia Learning: Influence of a Social Regulatory Support on Learning Performance and on Collaboration
}

\author{
Santiago Roger Acuña ${ }^{1, *}$ \& Gabriela López-Aymes ${ }^{2}$ \\ ${ }^{1}$ Faculty of Communication Sciences, Autonomous University of San Luis Potosi, San Luis Potosí, México \\ ${ }^{2}$ Faculty of Human Communication, Autonomous University of Morelos State, Cuernavaca, México \\ *Correspondence: Faculty of Communication Sciences, Autonomous University of San Luis Potosi, Avda. \\ Karakorum N ${ }^{a}$ 1245, Lomas 4 Sección, CP 78215, San Luis Potosí, S.L.P., México. Tel: 52-144-4418-6550. E-mail: \\ santiago.acuna@uaslp.mx
}

Received: October 3, 2016

Accepted: October 24, 2016 Online Published: November 17, 2016

doi:10.5430/jct.v5n2p83

URL: http://dx.doi.org/10.5430/jct.v5n2p83

\begin{abstract}
This paper analyzes the effects of a support aimed at favoring the social regulatory processes in a computer-supported collaborative learning (CSCL) environment, specifically in a comprehension task of a multimedia text about Psychology of Communication. This support, named RIDE (Saab, van Joolingen, \& van Hout-Wolters, 2007; 2012), consists in the instruction, prior to the learning task, from a series of communication rules extracted from literature about effective collaboration. The study was carried out with 60 college students, grouped in 20 triads. Each triad was assigned to one of two conditions: with social regulatory support or without support. The students did a face-to-face collaborative task of reading comprehension, using the strategy of collaborative construction of concept maps from the information presented in the multimedia material. The performance was valued according to the quality of the concept maps, and the level of collaboration perceived by each member of the teams was tested. We found that the condition with social regulatory support promoted higher quality concept maps; however, the social regulatory support had significant effect on the levels of collaboration perceived by the team members. In the conclusions are pointed the reach of these results for the design and implementation of collaborative interventions, based on the use of multimedia materials.
\end{abstract}

Keywords: multimedia learning; collaborative learning; social regulation; concept mapping; digital literacy

\section{Introduction}

The use of information and communication technologies (ICT) offers multiple possibilities to shape more flexible and open educational scenarios that promote the development of competences linked to the autonomous as well as collaborative learning. However, these competences are not reached solely with the presence of digital technology in instructional contexts. It requires a series of actions that promote a digital literacy, in other words, a true appropriation and strategic use of these technologies in the learning process of the students.

According to Lankshear and Knobel (2008), the idea of literacy makes reference to the socially recognized forms of generation, communicating and negotiating significant content. It is to say, it goes beyond the implementation of a tool. It implies a series of goal-oriented actions, in which new meanings are constructed. In this process both different cultural tools and knowledge systems are employed in order to accomplish a task or solve a problematic situation. Literacy may require technology, but also knowledge and skills which are put into play in those practices. For Lankshear and Knobel (2008) conventional literacies are based on the "printed letter", this is, in the cultural instruments related to the traditional book. While the new literacy is based on cultural tools, that have a different "technical substance", it also has a new "spiritual substance". In that sense, the new technique of ICT has to do with the digital which, in contrast with the analogic, provides attributes such as interactivity, hypertextual navigation and multimedia representation, in a fairly natural way. An appropriation of the technical dimension of the ICT requires the capacity to manage them, but also of the usage of a new language and meanings. However, the appropriation of the technique does not automatically leads to literacy. The key aspect is related with the new spirit or the new mentality enabled by ICT. This change in the way of thinking can only be reached when new ways of participation 
are constructed and strengthened, mediated by these tools. In other words, in accordance with Lankshear and Knobel (2008), a new literacy emerges when we become part of a community and share the same discourse, by means of the digital ICT.

A digital literacy also means the display of a series of high complexity mental processes from the students, even more when ICT are used on a collaborative way. For example, the multimedia collaborative learning demands from the apprentice the activation and integration of a series of cognitive, metacognitive and motivational mechanisms to process the textual and the pictorial information in an integrated and constructive way, which is presented in a non-linear way (Jonassen, Lee, Young, \& Laffey, 2005). This means that the fundamental actions involved in the comprehension of written texts (for example, getting information from the text establishing connections and relation between the ideas, and integrate the new information with prior knowledge), are accompanied by several processes linked to the navigation, information search, and evaluation of the information, besides a semantic processing that aims to the construction of mental representations that include textual and pictorial information (Mayer, 2005). Also, if this task is done in collaborative way, additional abilities should be displayed for the planning, management and supervision not only from the individual processes implied in learning but also from the peer collaboration processes that demands the collaborative activity (Winters \& Alexander, 2011). That is to say, the collaborative learning needs the student to self-regulate their own learning and, furthermore, to regulate the learning from other members in the group (co-regulation), also intervening in the regulation of the group as a whole (socially shared regulation) (Hadwin, Järvelä, \& Miller, 2011; Järvelä \& Hadwin, 2013). In this study, according to Volet, Vauras \& Salonen (2009), to reference the regulatory group activities implied in the collaborative learning, and to distinguish them from the self-regulation, the term social regulation is used. Likewise, social regulation encompasses : a) the established regulation in asymmetrical situations where a member of a group, by owning greater knowledge and regulation abilities, guides and supports the self- regulatory competence of the other members within the group (co-regulation); and also, b) the most advanced and complex regulatory processes that emerge when a group self-regulates together as a collective, in a symmetrical situation, where a common consciousness about targets can be built on a shared basis, the monitoring and supervision strategies and the management of exchanges which is a collaborative task (socially shared regulation) (Järvenoja, Järvelä \& Malmberg, 2015; Schoor \& Bannert, 2012; Volet et al., 2009).

Previous studies have noticed that, generally, the most sophisticated collaborative exchanges related with social regulation do not appear on a high level with frequency (Acuña, López Aymes, \& Gabino Campos, 2012; Chan 2001; Häkkinen \& Järvelä, 2006; Rogat \& Linnenbrink-Garcia 2011; Summers \& Volet 2010; Winters, \& Alexander, 2011). Moreover, the quality and complexity of this kind of social regulatory processing can be influenced by the type of task and, above all, by the support given in these instructional environments mediated by technology (Molenaar, Sleegers, \& van Boxtel, 2014; Saab et al., 2007; 2012; Schoor \& Bannert, 2012; Weinel \& Reimann, 2007).

In this paper we analyze the effects of a social regulatory support named RIDE -proposed by Saab et al. (2007, 2012)- in a learning situation, in which students build collaborative concept maps from the information provided on a digital multimedia text. This support consists in the previous instruction to the learning task in a set of communication rules extracted from literature about effective collaboration. Such rules are organized according to these four principles: Respect, Intelligent collaboration, Deciding together, and Encouraging. With this instructional socio regulatory support, we intended to promote more structured and organized exchanges and participation of the students in a face to face task of collaborative learning with multimedia and concept maps. Specifically, in this empirical study we seek to analyze the influence of the support system RIDE on the collaborative learning performance, as well as on the collaboration levels perceived by the participants in the collaborative teams.

\subsection{Collaborative Learning with Multimedia}

As it is well known, the new digital tools for learning constitute not only resources to share and build knowledge, but also instruments that can mold our way of thinking and learning. From a sociocultural perspective, these are cultural and symbolic artifacts that allow us to "go beyond ourselves", to get in touch with other minds and move forward together in the construction of representations that turn out to be mutually satisfying (Wells, 2004). In this sense, Scardamalia and Beretier (2006) have noted that the combined construction of meanings can be favored through the strategic use of these new technological tools.

Thus, the collaborative learning constitutes a socially mediated activity in which the knowledge is built in a combined, located and distributed way, from the dynamic interaction established between the learners, the sociocultural environment in which the activity is developed and the cultural instruments used for such activity (Salomon, 1995). In a collaborative task an instructional "scaffolded" scenario is configured, in which social 
interaction is enriched and allows exchanges, which drives the embracement of roles played in the group activity, but also new functions or the restructuring of the existent ones are internalized (Vygotsky, 1978; Wood, Bruner, \& Ross, 1976). For that, a structure of the collaborative processes is required, in order to facilitate the emergence of productive interaction. Therefore, the apprentices should assume a high level of active implication and take on responsibility of its own learning and also of their peers (Dillenbourg, 1999).

When used in collaborative learning contexts, the digital multimedia texts can promote: a) the activation of highly elaborated exchanges about the contents presented in the multimedia, bringing the comprehension through the discussion in which different ideas and points of view are revealed; and also, b) the explicitness of abilities, which are often kept implicit in individual tasks, especially the regulatory abilities related with the planning, monitoring, and the evaluation of the process that are required to put into play to achieve a shared deep comprehension of these multimedia contents (Winters \& Alexander, 2011; Winters \& Azevedo, 2005).

To do this, it is necessary that students must activate high level processes in order to achieve the target, especially of the metacognitive kind (Azevedo, Guthrie, \& Seibert, 2004, Azevedo \& Whiterspoon, 2009). These processes become critical for the self and social regulation of collaborative learning (Azevedo \& Whiterspoon, 2009; Molenaar et al., 2014; Winters \& Alexander, 2011). In the case of multimedia collaborative learning, besides the auto-regulation of its learning process, students must intervene in parallel with the intent of regulate not only the group construction process of meanings, but to manage the collaboration structures (Beishuizen, Wilhelm, \& Schimmel, 2004; Manlove, Lazonder, \& De Jong, 2006).

Some empirical studies about collaborative learning with multimedia have shown that the learning level achieved by students depends on the type and the quality of the interactions that were put into play in the groups (Azevedo, Winters, \& Moos, 2004; Sangin, Dillenbourg, Rebetez, Bétrancourt, \& Molinari, 2008; Winters \& Alexander, 2011). For example, Winters and Alexander (2011) investigated the role of regulatory learning processes in open-ended collaborative learning while using a hypermedia encyclopedia to learn about the human circulatory system. In their study with high school apprentices, they noticed that the dyads that attained a higher gain in their learning were implied in a high level of collaborative regulatory processes (e. g. seeking consensus, summarizing, taking notes, evaluating content, and expressing feeling of knowing), associated with building shared understanding, making high-quality inferences, and engaging in active processing strategies (Winters \& Alexander, 2011).

The regulation in a collaborative learning environment can target different aspects of the activity. Moreover, Saab et al. (2012) have identified two types of regulatory processes that the students can deploy: a) task regulation, which is aimed at regulating the cognitive activities during learning, and; b) team regulation, which implies the coordination of the collaboration between students. The formulation of questions, provide explanations and clarification are examples of related actions with the task regulation. While the interactions would refer to the organization and management of the group, such as, agreeing on taking turns for participation and generate agreements in the negotiation, are examples of team regulation.

To propitiate both types of processes in the collaborative activity it may be necessary to have support and additional guidelines, especially for those students who do not have collaborative experience. On the one hand, some instructional strategies -mediated by ICT and based on tasks such as collaborative concept mapping, collaborative inquiry learning, and collaborative problem solving- function as scaffolds, paired to provide structure to the learning activity, also allow to establish a target and to explicit the procedures to achieve it (Jonassen et al., 2005). On the other hand, it is possible to provide specific social regulatory support aimed to favor a productive interaction of the apprentices and enable a collaborative management for the co-construction of meaning. To provide an instruction previous to the collaborative learning task that promotes the communicative abilities development in students, would be an example of social regulatory support (Gijlers, Saab, van Joolingen, de Jong, \& van Hout-Wolters, 2009).

Both the regulation of the task and the specific social regulation are key to the effectiveness of the collaborative learning (Saab, 2012).

\subsection{Concept Mapping as Support for the Multimedia Collaborative Learning}

The concept mapping have been used as an instructional strategy to promote the comprehension and knowledge acquisition, as in individual learning situations as in collaborative ones (Chang, Sung, \& Chen, 2001; Hilbert \& Renkl, 2009, Nesbitt \& Adesope, 2013).

When the concept maps are used in a collaborative way, would work as frameworks that would favor the interaction of the apprentices and would allow the construction of shared meanings from the information presented in a specific instructional material. To that respect, van Boxtel, van der Linden, Roelofs, \& Erkens (2002) have pointed out that 
the use of the collaborative concept maps would prompt the students to involve in two kinds of actions, which are fundamental for the comprehension and learning: a) elaborative actions; and, b) actions of meaning negotiation. In the first place, the collaborative conceptual maps offer many possibilities to generate interactions that promote the knowledge elaboration. For example, it would increase the amount of information that is shared, showing it visually, in a concise and concrete way. The collaborative construction of the concept map leads to the students to identify the concepts presented on the text, share the meanings that they confer to these concepts and explain the existent relations between such ideas. In the second place, following van Boxtel et al. (2002), the collaborative concept mapping would cause adequate conditions for materialize actions of knowledge negotiation, in which the students, not only are forced to reflect on it and create their own knowledge, but they also need to consider, integrate and elaborate knowledge from their teammates.

It's not strange, therefore, that in a growing way it has been generalized the collaborative use of the concept maps in multiple learning setting, specially for the learning of diverse scientific concepts from the different kind of texts (Kinchin, De-Leij, \& Hay, 2005; van Boxtel, van der Linden, \& Kanselaar, 2000).

Regarding the use of collaborative concept maps in multimedia learning environments, in a previous investigation, Acuña and López-Aymes (2015) found differences in the type of concept mapping that college students elaborated collaboratively according to the type of learning materials they used (hypermedia in comparison to the traditional text). On that investigation the teams that worked with the traditional printed text, elaborated concept maps with a larger amount of concepts, whereas the nonlinear multimedia text condition groups, the concept maps showed a better hierarchical structure with a larger number of crosslinks. Furthermore, it could be noted that when working with nonlinear multimedia texts the concept maps would support a macro-structural, whereas concerning the lineal printed, the collaborative concept mapping construction would propitiate a better processing in terms of micro-structural level, allowing the recognition of a wider range of concepts (Amadieu \& Salmerón, 2014).

While research on collaborative concept mapping has found results that confirm the possibilities and advantages of concept maps - not only regarding to another kind of collaborative learning tasks (preparing abstracts, writing essays, making a poster) but also to the individual construction of concept maps - some studies have reported conflicting results concerning the positive effects of collaborative concept maps in learning (for a literature review see Basque \& Lavoie, 2006; Gao et al., 2007; Lupion \& de Cássia, 2010; Nesbitt \& Adesope, 2006). Therefore, one might think that the use of collaborative concept maps by itself does not guarantee that high levels of learning are fostered. As Nesbitt and Adesope (2006) mention, the potential advantages of collaborative concept maps are closely related both to the type and quality of interactions and the collaborative structure in which the use of collaborative concept mapping is delimited, such as the characteristics of the task and the system supports it provides.

\subsection{Supports for the Social Regulation in the Collaborative Learning}

Recent studies have emphasized the importance of providing different kinds of support that encourages the role of the social regulatory processes in the collaborative learning (Hadwin et al., 2011; Järvelä \& Hadwin, 2013; Järvenoja et al., 2105).

Thereon, a first group of support consists on providing different types of prompts, feedbacks or scaffoldings, whether directed to the motivational processes (Schoor, Kownatzki, Narciss, \& Körndle, 2014) or to the metacognitive (Molenaar et al., 2014; Molenaar, Roda, van Boxtel, \& Sleegers, 2012) implied in the the collaborative regulation. These supports can be provided by a technological tool which is included in the collaborative learning environment (Järvelä, Kirschner, Panadero, Malmberg, Phielix, Jaspers, Koivuniemi, \& Järvenoja, 2015; Molenaar et al., 2012, 2014).

A second way to support collaborative learning regulation is based on the script theory of guidance (Fischer, Kollar, Stegmann, \& Wecker, 2013). This support consists on offering a series of external scripts to students so they can structure their collaborative actions, for example, by inducing certain activities, prescribing determined sequences for the performance of each activity and also by distributing the specific roles that the students must play when they get involved in the collaborative task (Kollar, Fischer, \& Hesse, 2006; Kollar, Fischer, \& Slotta, 2007; Mäkitalo-Siegl, Kohnle, \& Fischer, 2011).

The third support option could be specifically oriented to develop the regulator processes in the collaborative task, thanks to the instruction and the communicative skills training in students, that is to say, through an explicit teaching from this type of abilities for collaboration. An example of such scaffolding is the procedure of tutorship between peers "ASK to THINK-TEL WHY", proposed by King (1997). This support consists on the specific communication skills teaching, for instance, listening to the explanation of a peer, to learn how to give elaborated explanations and to 
pose a specific question.

Another example of this kind of instructional support is the instructional scaffolding RIDE, suggested by Saab and contributors (Saab et al., 2007, 2012), which consists on the instruction from a series of collaboration rules that arise from different research projects concerning the effective collaboration (King, 1997; Mercer 1996). On this support, previous to the collaborative task, students are educated in a series of rules for collaboration, grouped together under the following four principles: a) Respect, which highlights the importance that each member of a team has the opportunity to speak and that every single idea given will be considered thoroughly; b) Intelligent collaboration, which relieves linked actions with sharing all the relevant information and to set out interest suggestions, make clear the given information, explain the given answers and properly carry out and accept criticisms; c) Deciding together, which highlights the necessity to explicitly state the agreements -previous to the decision making and the execution of an action-and take into account that is the group the responsible of the decisions and the actions (and not only one member in particular); finally, d)Encouragement, which refers to the value of promoting communicative actions, such as asking for explanations, ask if something was misunderstood, and give positive feedback. In a couple of empirical research projects Saab et al. $(2007,2012)$ tested this instructional RIDE support in a collaborative environment based in a virtual simulator for the Physics learning, where the high school students dyads could interact online through a chat. The instructional RIDE help promoted amongst the dyads a greater regulatory activity directed to the processes related to the coordination and management collaboration inside the teams (team regulation), despite the fact it didn't get to incise in a positive way on the results about learning nor in the cognitive activities regulation required by the task (task regulation), even though being combined with a technological tool of support for the hypothesis collaborative formulation (Saab et al., 2012).

Concretely, in this study we are interested on examining the effects of the support system RIDE (Saab et al., 2007) in a collaborative learning situation. The college students worked face-to-face, in triads, in the building of a concept map, from information presented in a multimedia digital text about a Psychology of Communication topic (interpersonal communication). In the experimental condition, the participants previous to the task, received an instructional session about the RIDE rules and, during the task, counted with the support of a summary document of these rules. The control condition didn't receive this previous instruction nor counted with a summary document about the RIDE rules. It was analyzed the influence of this RIDE support as in the learning performance reached by the teams (through the assessment of the quality of the concept maps) as in the levels of collaboration that the students referred to in each triad. It was expected that the support favored the levels of collaboration superior in the teams that received it compared to the teams that worked without the aid (Hypothesis 1) and that such aid favored the concept maps construction of higher quality (Hypothesis 2).

\section{Method}

\subsection{Participants and design}

The participants were 60 students from a Mexican university (34 women and 26 men) enrolled in psychology of communication course at the Autonomus University of San Luis Potosí (Mexico), that were grouped in 20 triads. The average age was $18.71(\mathrm{SD}=1.35)$. Each triad was assigned to one of the two conditions: collaborative task with RIDE support ( $n=10$ triads, with 16 women and $14 \mathrm{men}$ ) and collaborative task without support ( $n=10$ triads, with 18 women and $12 \mathrm{men}$ ). Almost all of the students have a middle-class socioeconomic level. It was controlled that there were no significant differences between the groups in respect to the reading comprehension and prior knowledge on the specific field (interpersonal communication) and in the elaboration of concept maps. The participants were instructed previously in the elaboration of concept maps, in two group sessions (big group) of 20 minutes each one. The student's participation was voluntary and they were awarded with credits for their courses.

\subsection{Materials}

The learning material consisted on a multimedia digital document on Interpersonal communication and the Double Bind Theory of Bateson (1985). The multimedia was structured into 5 content blocks that could be navigated in a nonlinear way, namely: - systems theory - axioms of communication - contributions and Bateson labor camps - bind and paradoxical theory and - necessary conditions for the double bind to appear. In the different blocks, written expository texts were combined in audio, narrated video and podcasts. The multimedia document was prepared with Prezi program. Since the structure of the multimedia was not linear, participants had the power to use and explore it at any order they wanted to.

In the instructional session about the RIDE rules, the next procedure was followed: a) in the first place, the students 
received one introduction about the meaning of collaboration and what actions turn out meaningful for a productive collaboration; b) in the second place, the four general principles (RIDE) were explained and the sub-rules were showed linked to each principle; c) in the third place, some examples were given for each one of the rules in a communicative situation of two people that are trying to solve a problem; d) finally, an exercise of simulated practice was done, where students should use different RIDE rules. While the collaborative task in the condition groups with RIDE support counted on a Powerpoint document that detailed the different RIDE rules. The students of the groups under this experimental condition could freely check this document.

\subsection{Instruments}

To assess the reading comprehension skills of the students, two tasks were applied. The Multimedia Comprehension Battery (abridged version) of Gernsbacher and Varner (1988), adapted by Díez and Fernández (1997) was administered to assess the reading comprehension level. In this test, students are asked to read a computerized text, "The Most Precious Gift", and after reading it, answer eight multiple-choice questions, each with five response options on the content presented in the text. The selected multimedia test battery controls the presentation time of the text, keeping it constant, and also provides a uniform time ( 20 seconds) to answer each of the assessment items. Each correct question is worth a point to a maximum of eight for the questionnaire in total.

The domain-specific prior knowledge level was examined by means of a questionnaire with 6 multiple-choice questions, each with four response options. For example, one of the items was: 4. Point out the correct idea: according to Watzlawick (1967), communication can be...a) only digital; b) only analogue; c) analogue and digital; d) none of the above. The maximum score that students can get in either set of questions is 6 points.

The quality of the concept maps was assessed according to the scoring system used by Liu (2011), in relation to the proposal of Novak and Gowin (1984). Scores were awarded by: number of relevant concepts (1 point for each significant concept), number of hierarchical levels ( 5 points for each valid hierarchical level), number of cross-links (10 points for each valid cross-link), and number of examples ( 1 point for each correct example). Furthermore, an adaptation was introduced into the assessment, as it considered the number of links correctly labeled ( 2 points for each correct link) (Hillbert \& Renkl, 2009).

To rate the level of cooperation perceived by participants, the Collaboration Questionnaire developed by Chan and Chan (2011), was used and developed based on the notion of collaborative knowledge construction described by Scardamalia and Bereiter (2006). This questionnaire consists on 12 items rated on a 5-point Likert scale, according to the collaborative experience that the students had in their respective teams. The different items reflect the 12 principles of collaborative learning proposed by Scardamalia (2002), and Scardamalia and Bereiter (2006), that emphasize collaboration in terms of shared cognitive responsibility and in the advancement of knowledge. The principles are related to: a) Improvable ideas (Principle 1); b) Community knowledge and collective responsibility (Principle 2); c ) High-level complex thinking (synthesis and building of more advanced knowledge) (Principle 3); d) Diversity of ideas (Principle 4); e) Democratizing knowledge (Principle 5); f) Epistemic agency and negotiation of meanings (Principle 6); g) Discourse aimed at the building of knowledge (Principle 7); h) Concurrent assessment (Principle 8); i) Symmetric advancement (Principle 9); j) Constructive uses of the information (Principle 10); k) Authentic problems and real ideas (Principle 11); and 12) Pervasive knowledge building (Principle 12). For example: "Our points of view and knowledge increased while working with others", refers to Principle 2 of Community knowledge.

\subsection{Procedure}

The study was carried out in four sessions. On the first two sessions (40 minutes each one of them), the students received instructions about the elaboration of concept maps and some questionnaires were applied to control the pre-test variables. On the first session the distinctive notes of the concept map were explained, presenting its elaboration technique; also, some of its applications and psycho pedagogic principles were also discussed and we addressed the relevance of using this tool in universities (Aguilar Tamayo, 2004). In addition, test of reading comprehension was applied. On the second session, a practice of modeling for concept mapping on contents from everyday life, using pencil and paper was carried out. Previous to the collaborative learning session, on the third session, the experimental condition received an instructional session about the use of the RIDE rules, following the dynamics previously presented. The control condition conducted a collaborative task (preparing abstracts) without receiving any instruction to promote collaborative communication. The face-to-face collaborative learning session (quarter session) lasted 60 minutes. At the beginning, the prior knowledge questionnaire of the specific domain was administered. Additionally, objectives and instructions to perform the task were explained. Subsequently, groups had 40 minutes to check the multimedia material and develop collaborative concept maps; and finally, participants 
answered the self-assessment questionnaire on collaboration in teams. The students created concept maps with digital pens (Livescribe Smartpen). Thereafter, the concept maps were transferred to CmapTools V. 5 [Computer Application] (Institute for Human and Machine Cognition HIMC, 2009) in order to ease the evaluation.

\section{Results}

A non-parametrical analysis was carried out to compare two independent samples, establishing the experimental condition (with or without the social regulatory RIDE support) as the group variable; and as dependent measurements, the different scores that assess both the quality of the concept map and the collaboration level perceived by students. Due to the impossibility to guarantee a normal distribution and the stability of the variance in variables, the non-parametric Mann-Whitney $U$ test was used, which is an excellent alternative to the parametric $t$ test.

For data analysis, we have worked with a level of statistical significance of $\mathrm{p}<.05$, and the Statistical Package for Social Science (SPSS) version 15.0 for Windows software was used.

Regarding the control variables, it was not fount significant differences between the two conditions considered for this study in any of the pre-test measures, it is to say, level of reading comprehension and level of previous knowledge of specific domain.

The quantitative analysis of the results (with the non- parametric Mann-Whitney $U$ test) shows the existence of significant effects of the social regulatory support in relation to some of the referred scores to the collaboration reached at the triads, as it is shown in Table 1.

Table 1. Levels of Collaboration in the Two Conditions

\begin{tabular}{lllll}
\hline & \multicolumn{2}{l}{ with RIDE support } & \multicolumn{2}{l}{ Without support } \\
\hline Improvable ideas & 4.13 & $(.77)$ & 4.26 & $(.63)$ \\
Communitarian knowledge and collective responsibility & 4.36 & $(.71)$ & 4.30 & $(.65)$ \\
Complex thinking of high level & 4.36 & $(.71)$ & 4.36 & $(.71)$ \\
Ideas diversity & 4.36 & $(.66)$ & 4.10 & $(.80)$ \\
Democratization of knowledge & 4.00 & $(.69)$ & 4.00 & $(.78)$ \\
Epistemology agency and meanings negotiation & 4.13 & $(.68)$ & 3.60 & $(.89)$ \\
Directed discourse to the knowledge building & 4.23 & $(.77)$ & 4.10 & $(.54)$ \\
Concurrent evaluation & 4.50 & $(.62)$ & 4.03 & $(.76)$ \\
Symmetric progress & 4.43 & $(.62)$ & 4.20 & $(.61)$ \\
Constructive use of the information & 3.70 & $(.98)$ & 3.06 & $(1.04)$ \\
Authentic problems and concrete ideas & 4.30 & $(.59)$ & 4.06 & $(.63)$ \\
Building of a generalized knowledge & 4.20 & $(.84)$ & 4.10 & $(.80)$ \\
& & & & \\
Total & 4.22 & $(.35)$ & 4.01 & $(.39)$ \\
\hline
\end{tabular}

Note. Values in columns represent means. Standard deviations are shown in brackets. Max points $=5$

There were significant differences in the total evaluation of the collaboration levels perceived by the students, in favor of the groups with the RIDE support groups (Mann-Whitney $U=295.00 ; Z=-2.291 ; p=0.022$ ). Also, it resulted significantly high the items referred to the epistemology agency and meanings negotiation (Mann-Whitney $\mathrm{U}=$ 297.00; $Z=-2.497 ; p=0.013$ ), Concurrent evaluation (Mann-Whitney $U=298.00 ; Z=-2.421 ; p=0.015$ ) and Constructive use of the information (Mann-Whitney $U=298.00 ; Z=-2.338 ; p=0.015$ ), in favor of the groups with the RIDE support.

Also, the statistical non-parametric analysis showed evidence about the existence of significant differences between the two conditions about the quality of the conceptual maps, in the total score and in scores of some of the revised indicators from the conceptual maps, also in favor of the condition that received the RIDE support (See Table 2). 
Table 2. Performances of the Two Conditions in Variables Related to Quality of Collaborative Concept Maps

\begin{tabular}{lll}
\hline & With RIDE support & Without support \\
\hline Concept score & $14.20(7.42)$ & $9.90(1.95)$ \\
Correct links score & $17.40(7.93)$ & $9.60(3.49)$ \\
Correct cross links score & $.00(.00)$ & $.33(1.82)$ \\
Valid hierarchy levels score & $21.00(6.74)$ & $16.50(3.25)$ \\
Examples score & $.10(.30)$ & $.00(.00)$ \\
Total score & $52.70(20.91)$ & $36.33(7.68)$ \\
\hline
\end{tabular}

Note. Values in columns represent means. Standard deviations are shown in brackets.

In such sense, it was observed a significant difference in relation to the total score from collaborative concept maps (Mann-Whitney $\mathrm{U}=177.00 ; \mathrm{Z}=-4.049 ; \mathrm{p}=0.00$ ). Also, the condition with RIDE support fostered in a meaningful way the collaborative making of conceptual maps with higher punctuation in the indicators that refer to concepts (Mann-Whitney $\mathrm{U}=144.00 ; \mathrm{Z}=-4.569 ; \mathrm{p}=0.00$ ) and hierarchies (Mann-Whitney $\mathrm{U}=256.50 ; \mathrm{Z}=-2.99 ; \mathrm{p}=0.003$ ).

\section{Discussion and Conclusions}

In this study, the RIDE support (Saab et al., 2007; 2012), has been tested in a multimedia learning task with collaborative concept maps. This support provides an instructional framework aimed at developing on students the communicative abilities associated to a series of principles and efficient rules for collaboration. In the first place, the results obtained from the empirical study show that, in effect, the groups corresponding to the experimental condition that have used such support, valued positively some indicators related to the levels of collaboration reached during the task. These results are consistent with previous studies developed by Saab et al. $(2007 ; 2012)$ that demonstrated a positive effect of the RIDE framework in the regulatory activities involved in collaboration, when secondary school students developed their learning tasks by investigation about a Physics topic (particles collision) in instructional environments based on computers (simulation program).

In this case, it can be pointed out that promoting processes linked with the co-regulation of the interaction and the exchanges in collaborative multimedia learning with concept mapping through the RIDE support, it has positive effects not only on the collaboration of the students, but also on the performance in the collaborative concept mapping.

In effect, the RIDE support turned out to be effective to foster the elaboration of concept maps of higher quality level than from the groups with the no-aid condition. This was shown not only in the total score from the conceptual maps, but also in some specific measures, referred to the number of concepts, of correct semantic links and to the levels and the relevance of conceptual hierarchies established in the different maps. In that sense, as a possible explanation to the effects of the framework proposed in the quality of the concept maps, it could be suggested that this support, in the beginning, would allow the students to free cognitive and metacognitive resources to allocate them to higher levels of processing linked to the regulation of the learning task. This effect, was not found in previous studies from Saab et al. (2007; 2012), probably because the collaborative activity was developed in a more complex instructional environment and the interaction was mediated by a digital chat. In this study the apprentices worked face-to-face in a collaborative environment with a multimedia text, less sophisticated than the virtual environment with the simulator. In this study, the evaluation of the collaboration levels that perceived the students in their teams, reached really high scores for both conditions (above 4 with a max of 5). It would be advisable to complement this analysis with other instruments, or through qualitative procedures that pick up the exchange that put in play the students, in on-line mode, it is to say, during the same time that the collaborative task is developed.

\section{Acknowledgements}

This work is part of a series of studies in progress about collaboration and digital technologies that are carried out within the framework of the research project called "Management and communicative innovation in organizations" corresponding to the Thematic Network of Academic Collaboration " Management, Culture and Communication in Organizations ", with support from PRODEP-SEP (Mexico) DSA / 103.5 / 15/11048 (UASLP-CA-232), in which the first author participates. Further the present research was supported by funding from Quality Strenghtening 
Programme in Educational Institutions from the Secretariat of Public Education of Mexico (P/PROFOCIE-2014-24MSU0011E-04), awarded to the first author. The authors also acknowledge the assistance provided by Mauricio López-Aymes and Alicia Robles-García for the translation of this article and Juan Felipe López-Aymes for revising the English grammar. The authors also appreciate the thoughtful revisions and helpful suggestions made by the associate editor and two anonymous reviewers, which clearly contributed to substantially improving the paper.

\section{References}

Acuña S. R., \& López-Aymes, G. (2015). El aprendizaje colaborativo multimedia con mapas conceptuales: Efectos de un texto multimedia en el rendimiento en la tarea y en el nivel de colaboración. TEXTOS: Revista Internacional de Aprendizaje y Cibersociedad, 19(1), 1-11.

Acuña, S., López-Aymes, G., \& Gabino, M. A. (2012). Co-regulación y función comunicativa de los intercambios en el aprendizaje colaborativo con mapas conceptuales. In A. J. Cañas, J. D. Novak, J. Vanhear (Eds.), Concept Maps: Theory, Methodology, Technology (Vol. 1) (pp. 65-72).Valletta, Malta: University of Malta and HIMC.

Aguilar-Tamayo, M. F. (2004). El Mapa Conceptual: Un texto a interpretar. In A. J. Cañas, J. D. Novak y F. M. González (Eds.), Concept Maps: Theory, Methodology, Technology. Proceedings of the First International Conference on Concept Mapping (Vol. I) (pp. 31-38). Pamplona, España: Universidad Pública de Navarra.

Amadieu, F., \& Salmerón, L. (2014). Concept maps for comprehension and navigation of hypertexts. In: R. Hanewald, \& D. Ifenthaler (Eds.), Digital Knowledge Maps in Education (pp. 41-59). Nueva York: Springer.

Azevedo, R., \& Witherspoon, A. M. (2009). Self-regulated learning with hypermedia. In D. J. Hacker, J. Dunlosky, \& A. C. Graesser (Eds.), Handbook of metacognition in education (pp. 319-339). Mahwah, NJ: Routledge.

Azevedo, R., Guthrie, J. T., \& Seibert, D. (2004). The role of self-regulated learning in fostering students' conceptual understanding of complex systems with hypermedia. Journal of Educational Computing Research, 30, 87-111. http://dx.doi.org/10.2190/DVWX-GM1T-6THQ-5WC7

Azevedo, R., Winters, F. I., \& Moos, D. C. (2004). Can students collaboratively use hypermedia to learn science? The dynamics of self- and other-regulatory processes in an ecology classroom. Journal of Educational Computing Research, 31(3), 215-245. http://dx.doi.org/10.2190/hft6-8eb1-tn99-mjvq

Basque, J., \& Lavoie, M.-C. (2006). Collaborative concept mapping in education: major research trends. In A. J. Cañas, J. D. Novak (Eds), Concept Maps: Theory, Methodology, Technology. Proceeding of the Second International Conference on Concept Mapping (Vol. 1) (pp. 79-86). San José, Costa Rica: Universidad de Costa Rica.

Bateson, G. (1985). Pasos hacia una ecología de la mente. Buenos Aires: Carlos Lohlé.

Beishuizen, J., Wilhelm, P., \& Schimmel, M. (2004). Computer-supported inquiry learning: effects of training and practice. Computers \& Education, 42, 389-402. http://dx.doi.org/10.1016/j.compedu.2003.10.003

Chan C.K. (2001). Peer collaboration and discourse patterns in learning from incompatible information. Instructional Science, 29, 443-479. http://dx.doi.org/10.1023/A:1012099909179

Chan, C., \& Chan, Y. (2011). Students' views of collaboration and online participation in Knowledge Forum. Computers and Education, 57, 1445-1457. http://dx.doi.org/10.1016/j.compedu.2010.09.003

Chang, K. E., Sung, Y. T., \& Chen, S. F. (2001). Learning through computer-based concept mapping with scaffolding aid. Journal of Computer Assisted Learning, 17(1), 21-33. http://dx.doi.org/10.1111/j.1365-2729.2001.00156.x

Díez, E., \& Fernández, A. (1997). Batería multimedia de comprensión (versión abreviada). Salamanca, Es: Universidad de Salamanca.

Dillenbourg, P. (1999). What do you mean by collaborative learning? In P. Dillenbourg (Ed.), Collaborative-learning: Cognitive and computational approaches (pp. 1-19). Oxford: Elsevier.

Fischer, F., Kollar, I., Stegmann, K., \& Wecker, C. (2013). Toward a script theory of guidance in computer-supported collaborative learning. Educational Psychologist, 48(1), 56-66. http://dx.doi.org/10.1080/00461520.2012.748005.

Gao, H., Shen, E., Losh, S., \& Turner, J. (2007). A review of studies on collaborative concept mapping: What have we learned about the technique and what is next? Journal of Interactive Learning Research, 18(4), 479. 
Gernsbacher, M. A., \& Varner, K. R. (1988). The multimedia comprehension battery. Eugene, OR: University of Oregon, Institute of Cognitive and Decision Sciences.

Gijlers, H., Saab, N., van Joolingen, W.R., de Jong, T., \& van Hout-Wolters, B.H.A.M. (2009). Interaction between tool and talk: how instruction and tools support consensus building in collaborative inquiry-learning environments. Journal of Computer Assisted Learning, 25, 252-267. http://dx.doi.org/10.1111/j.1365-2729.2008.00302.x

Hadwin, A. F., Järvelä, S., \& Miller, M. (2011). Self-regulated, co-regulated, and socially shared regulation of learning. In B. J. Zimmerman \& D. H. Schunk (Eds.), Handbook of self-regulation of learning and performance (pp. 65-84). New York: Routledge.

Häkkinen, P., \& Järvelä, S. (2006). Sharing and constructing perspectives in web-based conferencing. Computers and Education, 47(4), 433-447. http://dx.doi.org/10.1016/j.compedu.2004.10.015

Hilbert, T. S., \& Renkl, A. (2009). Learning how to use a computer-based concept-mapping tool: Self-explaining examples helps. Computers in Human Behavior, 25, 267-274. http://dx.doi.org/10.1016/j.chb.2008.12.006

IHMC (2009). CmapTools V. 5 [Software Applications].Institute for Human and Machine Cognition. (http://cmap.ihmc.us).

Järvelä, S., \& Hadwin, A. F. (2013). New frontiers: Regulating learning in CSCL. Educational Psychologist, 48(1), 25-39. http://dx.doi.org/10.1080/00461520.2012.748006

Järvelä, S., Kirschner, P. A., Panadero, E., Malmberg, J., Phielix, C., Jaspers, J., Koivuniemi, M., \& Järvenoja, H. (2015). Enhancing Socially Shared Regulation in Collaborative Learning Groups: Designing for CSCL Regulation Tools. Educational Technology Research and Development, 63, 125-142. http://dx.doi.org/10.1007/s11423-014-9358-1

Järvenoja, H., Järvelä, S., \& Malmberg, J. (2015) Understanding Regulated Learning in Situative and Contextual Frameworks, Educational Psychologist, 50(3), 204-219. http://dx.doi.org/10.1080/00461520.2015.1075400

Jonassen, D. H., Lee, C. B., Young, C. C., \& Laffey, J. (2005). The Collaboration principle in Multimedia Learning. In R. Mayer (Ed.), Cambridge Handbook of Multimedia Learning (pp. 247-270). Cambridge: Cambridge University Press.

Kinchin, I. M., De-Leij, F. A., \& Hay, D. B. (2005). The evolution of a collaborative concept mapping activity for undergraduate microbiology students. Journal of Further and Higher Education, 29(1), 1-14. http://dx.doi.org/10.1080/03098770500037655

King, A. (1997). ASK to THINK-TEL WHY: a model of transactive peer tutoring for scaffolding higher level complex learning. Educational Psychologist, 32, 221-235. http://dx.doi.org/10.1207/s15326985ep3204_3

Kollar, I., Fischer, F., \& Hesse, F. W. (2006). Collaboration scripts - a conceptual analysis. Educational Psychology Review, 18(2), 159-185. http://dx.doi.org/10.1007/s10648-006-9007-2

Kollar, I., Fischer, F., \& Slotta, J. D. (2007). Internal and external scripts in computer-supported collaborative inquiry learning. Learning and Instruction, 17(6), 708-721. http://dx.doi.org/ 10.1016/ j.learninstruc.2007.09.021

Lankshear, C., \& Knobel, M. (2008). Nuevos alfabetismos. Su práctica cotidiana y el aprendizaje en el aula $\left(2^{\circ}\right.$ Edición). Madrid: Morata.

Liu, P. (2011). A study on the use of computerized concept mapping to assist ESL learners' writing. Computers \& Education 57(4), 2548-2558. http://dx.doi.org 10.1016/j. compedu. 2011. 03. 015

Lupion, P., \& de Cássia, R. (2010). Handbook of research on collaborative learning using concept mapping. New York: Information Science Reference.

Mäkitalo-Siegl, K., Kohnle, C., \& Fischer, F. (2011). Computer-supported collaborative inquiry learning and classroom scripts: Effects on help-seeking processes and learning outcomes. Learning and Instruction, 21(2), 257-266. http://dx.doi.org/10.1016/j.learninstruc.2010.07.001

Manlove, S., Lazonder, A.W., \& De Jong, T. (2006). Regulative support for collaborative scientific inquiry learning. Journal of Computer Assisted Learning, 22, 87-98. http://dx.doi.org/10.1111/j.1365-2729.2006.00162.x

Mayer, R. E. (2005). Cognitive theory of multimedia learning. In R. E. Mayer (Ed.), The Cambridge handbook of multimedia learning (pp. 31-48). New York, NY: Cambridge University Press. 
Mercer N. (1996) The quality of talk in children's collaborative activity in the classroom. Learning and Instruction, 6 , 359-375. http://dx.doi.org/10.1016/s0959-4752(96)00021-7

Molenaar, I., Roda, C., van Boxtel, C., \& Sleegers, P. (2012). Dynamic scaffolding of socially regulated learning in a computer-based learning environment. Computers \& Education, 59(2), 515-523. http://dx.doi.org/10.1016/j.compedu.2011.12.006

Molenaar, I., Sleegers, P., \& van Boxtel, C. (2014). Metacognitive scaffolding during collaborative learning: a promising combination. Metacognition and learning, 9(3), 309-332. http://dx.doi.org/10.1007/s11409-014-9118-y

Nesbit, J. C., \& Adesope, A. O. (2006). Learning with concept and knowledge maps: A meta-analysis. Review of Educational Research, 76, 413-448. http://dx.doi.org/10.3102/00346543076003413

Nesbit, J. C., \& Adesope, A. O. (2013). Concept maps for learning. In G. M. Schraw, M. T. McCrudden, \& D. Robinson (Eds.), Learning Through Visual Displays (pp. 303-328). Charlotte, NC: Information Age.

Novak, J. D., \& Gowin, D. B. (1984). Learning how to learn. London: Cambridge University.

Rogat, T. K., \& Linnenbrink-Garcia, L. (2011). Socially shared regulation in collaborative groups: An analysis of the interplay between quality of social regulation and group processes. Cognition and Instruction, 29(4), 375-415. http://dx.doi.org/ 10.1080/07370008.2011.607930

Saab, N. (2012). Team regulation, regulation of social activities or co-regulation: Different labels for effective regulation of learning in CSCL. Metacognition and Learning, 7, 1-6. http://dx.doi.org/10.1007/s11409-011-9085-5

Saab, N., van Joolingen, W. R., \& van Hout-Wolters, B. (2007). Supporting communication in a collaborative discovery learning environment: The effect of instruction. Instructional Science, 35, 73-98. http://dx.doi.org/10.1007/s11251-006-9003-4

Saab, N., van Joolingen, W. R., \& van Hout-Wolters, B. (2012). Support of the collaborative inquiry learning process: influence of support on task and team regulation. Metacognition and Learning, 7, 7-23. http://dx.doi.org/10.1007/s11409-011-9068-6.

Salomon, G. (1995). Distribuited cognitions: Psychological and educational considerations. Cambridge, UK.: Cambridge, University Press.

Sangin, M., Dillenbourg, P., Rebetez, C., Bétrancourt, M., \& Molinari, G. (2008). The effects of animations on verbal interaction in computer supported collaborative learning. Journal of Computer Assisted Learning, 24(5), 394-406. http://dx.doi.org/10.1111/j.1365-2729.2008.00275.x

Scardamalia, M. (2002). Collective Cognitive Responsibility for the Advancement of Knowledge. In B. Smith (Ed.), Liberal Education in a Knowledge Society (pp. 67-98). Chicago: Open Court.

Scardamalia, M., \& Bereiter, C. (2006). Knowledge building: theory, pedagogy, and technology. In R. K. Sawyer (Ed.), The Cambridge handbook of the learning sciences (pp. 97-119). New York: Cambridge University Press.

Schoor, C., \& Bannert, M. (2012). Exploring regulatory processes during a computer-supported collaborative learning task using process mining. Computers in Human Behavior, 28(4), 1321-1331. http://dx.doi.org/10.1016/j.chb.2012.02.016

Schoor, C., Kownatzki, S., Narciss, S., \& Körndle, H. (2014). Effects of Feeding Back the Motivation of a Collaboratively Learning Group. Electronic Journal of Research in Educational Psychology, 12(1), 191-210. http://dx.doi.org/10.14204/ejrep.32.13077

Summers, M., \& Volet, S. (2010). Group work does not necessarily equal collaborative learning: evidence from observations and self-reports. European Journal of Psychology Educational, 25, 473-492. http://dx.doi.org/ 10.1007/s10212-010-0026-5

van Boxtel, C., van der Linden, J. L., \& Kanselaar, G. (2000). Collaborative learning tasks and the elaboration of conceptual knowledge. Learning and Instruction 10, 311-330. http://dx.doi.org/10.1016/S09594752(00)00002-5

van Boxtel, C., van der Linden, J. L., Roelofs, E., \& Erkens, G. (2002). Collaborative concept mapping: Provoking and supporting meaningful discourse. Theory into Practice, 4l(1), 40-46. http://dx.doi.org/10.1207/s15430421tip4101_7 
Volet, S., Vauras, M., \& Salonen, P. (2009). Self- and social regulation in learning contexts: An integrative perspective. Educational Psychologist, 44(4), 215-226. http://dx.doi.org/10.1080/00461520903 213584

Vygotsky, L. (1978). Mind in Society: the Development of Higher Psychological Process. Cambridge, MA: Harvard University Press.

Weinel M., \& Reimann P. (2007). Coordination dynamics in CSCL based chat logs. In C. A. Chinn, G..Erkens, \& S. Putambekar (Eds.), Proceedings CSCL'07 of the 8th International Conference on Computer Supported Collaborative Learning (pp. 773-775). New Brunswick, NJ: International Society of the Learning Sciences.

Wells, G. (2004). El papel de la actividad en el desarrollo y la educación. Infancia y Aprendizaje, 27(2), 165-187.

Winters, F. I., \& Alexander, P. A. (2011). Peer collaboration: the relation of regulatory behaviors to learning with hipermedia. Instructional Science, 39, 407-427. http://dx.doi.org/10.1007/s11251-010-9134-5

Winters, F. I., \& Azevedo, R. (2005). High-school students' regulation of learning during computer-based science inquiry. Journal of Educational Computing Research, 33(2), 189-217. http://dx.doi.org/10.2190/F7HM-9JN5-JUX8-4BM9

Wood, D. J., Bruner, J. S., \& Ross, G. (1976). The role of tutoring in problem solving. Journal of Child Psychology and Psychiatry, 17, 89-100. http://dx.doi.org/10.1111/j.1469-7610.1976.tb00381.x 